\title{
Reduction of Neuromuscular Activity Is Required for the Rescue of Motoneurons from Naturally Occurring Cell Death by Nicotinic-Blocking Agents
}

\author{
Ronald W. Oppenheim,, David Prevette, ${ }^{1}$ Anselem D'Costa, ${ }^{1}$ Siwei Wang, ${ }^{1}$ Lucien J. Houenou, ${ }^{1}$ and \\ J. Michael Mclntosh² \\ ${ }^{1}$ Department of Neurobiology and Anatomy and the Neuroscience Program, Wake Forest University Medical School, \\ Winston-Salem, North Carolina 27157, and 2Departments of Biology and Psychiatry, University of Utah, \\ Salt Lake City, Utah 84112
}

\begin{abstract}
Spinal motoneurons (MNs) in the chick embryo undergo programmed cell death coincident with the establishment of nervemuscle connections and the onset of synaptic transmission at the neuromuscular junction. Chronic treatment of embryos during this period with nicotinic acetylcholine receptor (nAChR)blocking agents [e.g., curare or $\alpha$-bungarotoxin $(\alpha$-BTX)] prevents the death of MNs. Although this rescue effect has been attributed previously to a peripheral site of action of the nAChRblocking agents at the neuromuscular junction (NMJ), because $\mathrm{nAChRs}$ are expressed in both muscle and spinal cord, it has been suggested that the rescue effect may, in fact, be mediated by a direct central action of $\mathrm{nAChR}$ antagonists. By using a variety of different $n A C h R$-blocking agents that target specific muscle or neuronal nAChR subunits, we find that only those agents that act on muscle-type receptors block neuromuscular
\end{abstract}

activity and rescue MNs. However, paralytic, muscular dysgenic mutant chick embryos also exhibit significant increases in $\mathrm{MN}$ survival that can be further enhanced by treatment with curare or $\alpha$-BTX, suggesting that muscle paralysis may not be the sole factor involved in MN survival. Taken together, the data presented here support the argument that, in vivo, nAChR antagonists promote the survival of spinal MNs primarily by acting peripherally at the NMJ to inhibit synaptic transmission and reduce or block muscle activity. Although a central action of these agents involving direct perturbations of $\mathrm{MN}$ activity may also play a contributory role, further studies are needed to determine more precisely the relative roles of central versus peripheral sites of action in $\mathrm{MN}$ rescue.

Key words: motoneurons; activity; cell death; nicotinic receptors; spinal cord; embryo; chicken; acetylcholine
During discrete stages of development, approximately one-half of all postmitotic motoneurons (MNs) degenerate by a pathway most closely resembling apoptosis (Hamburger, 1975; Chu-Wang and Oppenheim, 1978; Oppenheim, 1991). Before programmed cell death (PCD), MNs differentiate normally and establish provisional synaptic contacts with their peripheral muscle targets (Oppenheim et al., 1978; Oppenheim and Chu-Wang, 1983; Dahm and Landmesser, 1988, 1991). Competition for trophic factors is one of the major strategies used by developing MNs for determining which cells survive and which cells undergo PCD (Dohrmann et al., 1986; Oppenheim et al., 1988, 1993; Bloch-Gallego et al., 1991; Oppenheim, 1996).

In the chick embryo, the period of MN PCD coincides with the onset of muscle innervation and neuromuscular function when neurally mediated embryonic movements (motility) can first be observed (Oppenheim, 1987). Activity blockade during the period of normal MN death rescues most MNs from PCD, and the rescued cells can be maintained as long as activity remains blocked (Pittman and Oppenheim, 1978, 1979). However, after treatment is stopped and activity recovers, the rescued cells undergo a delayed cell death (also see Landmesser and Szente, 1986). In contrast to effects of activity blockade, direct electrical stimulation of the hindlimb muscles in ovo increases MN death (Oppenheim and Nunéz, 1982).

After the report of the rescue of MNs by activity blockade, further analysis revealed that there were increased numbers of

\footnotetext{
Received Jan. 4, 2000; revised May 18, 2000; accepted June 2, 2000.

This work was supported by National Institutes of Health Grants NS 20420 and NS 31380 to R.W.O. and MH 53631 and GM 48677 to J.M.M. and by a grant from the Muscular Dystrophy Association to L.J.H.

Correspondence should be addressed to Dr. Ronald W. Oppenheim, Department of Neurobiology and Anatomy, Wake Forest University Medical School, Medical Center Boulevard, Winston-Salem, NC 27157-1010. E-mail: roppenhm@wfubmc.edu.

Copyright (C) 2000 Society for Neuroscience $0270-6474 / 00 / 206117-08 \$ 15.00 / 0$
}

axons and synapses in the limb muscles of the activity-blocked embryos (Pittman and Oppenheim, 1979; Oppenheim and ChuWang, 1983; Oppenheim et al., 1989). Later studies by Lynn Landmesser and her colleagues showed that this hyperinnervation of activity-blocked muscle could be detected at the very onset of normal PCD before any significant MN loss had occurred (Landmesser, 1992). From this, it was postulated that inactivity-induced hyperinnervation may be the cause rather than the effect of reduced MN PCD (Oppenheim, 1989). More specifically, it was argued that a primary action of activity blockade was increased branching and synapse formation of MN axons via the blockade of muscle nAChRs, which in turn rescued MNs by providing them with increased access (via nerve terminals) to muscle-derived neurotrophic factors [the access hypothesis (Oppenheim, 1989)]. An alternative explanation of $\mathrm{MN}$ rescue by activity blockade is that muscle activity is inversely related to the synthesis (production) or release of a muscle-derived neurotrophic factor [the production hypothesis (Tanaka, 1987; Oppenheim, 1989)]. Two independent attempts to test the production hypothesis failed to support this idea (Tanaka, 1987; Houenou et al., 1991), whereas several lines of evidence are consistent with the access hypothesis (Tang and Landmesser, 1993; Oppenheim et al., 1997; Calderó et al., 1998; D'Costa et al., 1998).

With the recent recognition that neurons in the CNS, including the spinal cord, express nicotinic acetylcholine receptors (nAChRs), yet another hypothesis for explaining the effects of activity blockade on MN survival has been postulated (Hory-Lee and Frank, 1995). According to this hypothesis, MN survival after activity blockade is thought to result from the direct action of nicotinic receptor blockers such as curare and $\alpha$-bungarotoxin $(\alpha$-BTX) on neuronal nAChRs rather than on peripheral muscle nAChRs, and neither peripheral nor central neuromuscular activity is considered to be necessary for MN survival. Rather, neuronal nAChRmediated changes in intracellular calcium levels in the soma, den- 
drites, or axon terminal are suggested to mediate MN survival by curare treatment (Hory-Lee and Frank, 1995; Posada and Clarke, 1999). However, nicotinic blockers have also been shown to have differential functional effects on central versus peripheral nAChRs during the period of MN cell death (Landmesser and Szente, 1986; Milner and Landmesser, 1999; Usiak and Landmesser, 1999), raising the additional possibility that these agents may promote $\mathrm{MN}$ survival by acting at both sites, to perturb neuromuscular activity. The present studies were undertaken in an attempt to examine the role of neuronal and muscle-type nAChRs in MN survival in the chick embryo during activity blockade and to determine whether activity blockade is even required in this situation.

Parts of this paper have been published previously (Oppenheim et al., 1996).

\section{MATERIALS AND METHODS}

Eggs and embryos. Fertilized chicken eggs were obtained from Hubbard Farms (Statesville, NC) and incubated in a turning incubator at $37^{\circ} \mathrm{C}$ and $60 \%$ relative humidity. In addition, eggs from a cross of heterozygous carriers of the crooked neck $(\mathrm{cn})$ gene were obtained from the Department of Animal Genetics (University of Connecticut) and were also incubated as described above. Homozygous $\mathrm{cn} / \mathrm{cn}$ mutant embryos were identified on embryonic day 4 (E4) by the total absence of neuromuscular activity (Oppenheim et al., 1997). Both heterozygous embryos $(\mathrm{cn} /+)$ and homozygous wild-type embryos $(+/+)$ were used as controls. After various experimental manipulations, all embryos were killed by decapitation, and their age was determined by reference to the stage series of Hamburger and Hamilton (1951).

In ovo treatment. For treatment of embryos in vivo with neurotoxins and pharmacological agents, a window was made in the shell over the embryo on E3-E4, exposing the underlying chorioallantoic membrane (CAM) and providing a means for observing and recording motility of the embryo. Experimental or control (saline) treatments were administered in 50-200 $\mu$ l volumes onto the highly vascularized CAM. This provides an efficient, relatively noninvasive means of systemically exposing chick embryos to a variety of different agents that, because of the absence of the blood-brain barrier at the ages used here (Stewart and Wiley, 1981; Risau and Wolburg, 1990), reach both central and peripheral sites. However, because of the presence of the yolk sac, amnion, and other extraembryonic tissues and fluids in the egg, the distribution of drugs and toxins in the avian egg is complex and temporally dynamic, making it difficult to estimate how much of these agents actually reach the appropriate receptors in the embryo. Between observations (or injections) the window in the shell was sealed with Parafilm, and the eggs were returned to the incubator. The following agents were used for in vivo studies: D-tubocurarine (curare), $\alpha$-BTX, and decamethonium (Sigma, St. Louis, MO); methyllycaconitine citrate (MLA) and dihydro- $\beta$-erythroidine hydrobromide (DH $\beta$ E) (Research Biochemicals, Natick, MA); and the snail $\alpha$ and $\alpha$ A conotoxins EIVA, IMI, MI, GI, AuIB, and M II (provided by J. Michael McIntosh). Embryos were treated once or twice daily with these agents beginning on E5 or E6. The doses used for each agent are provided in the appropriate table and figure legends. The doses of curare, $\alpha$-BTX, and decamethonium used here are based on previous studies in which motility and MN survival were assessed (Pittman and Oppenheim, 1978, 1979; Oppenheim and ChuWang, 1983). The doses of all the other agents used here were based on published doses used to study mammalian nerve-muscle and nerve activity (Johnson et al., 1995; Cartier et al., 1996; Jacobsen et al., 1997; Luo et al., 1998).

Neuromuscular activity. The neurally mediated movements (motility) of the embryos were recorded blind as to treatment once or several times daily for $5 \mathrm{~min}$ as described previously (Oppenheim, 1975). Briefly, al movements of the embryo were counted with a hand counter while the embryo was observed through the window in the shell using a binocular microscope at $5 \times$ with the egg in a temperature- and humidity-controlled chamber.

Histology and cell counts. Embryos were killed and staged, and the thoracolumbar region was placed in Carnoy's fixative, processed, embedded in paraffin, serially sectioned $(10-12 \mu \mathrm{m})$, and stained with thionin. All MNs in every 10th section through the entire lumbar enlargement were counted blind at $400 \times$, and the totals were multiplied by 10 as an estimate of the total number of lumbar MNs. The criteria used for counting MNs have been described previously (Clarke and Oppenheim, 1995) and shown to provide a valid and reliable means for accurately assessing $\mathrm{MN}$ numbers. In a few of the embryos (curare, $\alpha$-BTX, and control; $n=3$ per group) MNs were counted separately in each of the eight lumbar segments using the adjacent dorsal root ganglion as a means of segment identity. Finally, to assess directly the effects of paralytic and nonparalytic doses of curare and $\alpha$-BTX on PCD, we counted the number of degenerating (pyknotic) MNs on E7.5, a time of peak MN loss.

Axonal branching and synaptogenesis. The number of axonal branches and synapses was assessed blind in whole mounts of two hindlimb muscles, the iliofibularis and the posterior iliotibialis, on E9 according to methods described previously in detail (Dahm and Landmesser, 1991; Oppenheim et al., 1997). Nerves and nerve branches were visualized immunocytochemically using an anti- $\beta$-tubulin monoclonal antibody TuJ1 (a gift from A. Frankfurter), and neuromuscular synapses were defined as sites of colocalization of immunolabeling for SV2, a presynaptic vesicle monoclonal antibody (a gift from K. Buckley), with postsynaptic AChR clusters that were visualized with rhodamine-labeled $\alpha$-BTX (Molecular Probes, Eugene, OR).

\section{RESULTS}

\section{Motility after treatment with curare or $\alpha$-BTX}

In a recent study examining the effects of curare and $\alpha$-BTX on motility and MN survival, it was reported that doses of these agents that failed to reduce motility (so-called "nonparalytic" doses) nonetheless promoted MN survival (Hory-Lee and Frank, 1995). From this, it was argued that neither neuromuscular blockade nor inhibition of CNS activity was required for $\mathrm{MN}$ rescue by these agents. However, because at most of the ages examined by these authors motility was only assessed once each day, $\sim 23 \mathrm{hr}$ after each daily drug treatment, it is conceivable that these embryos may have exhibited reduced motility during the $20+$ hr before each recording. To examine this, we recorded motility at 2, 6, 12, and $23 \mathrm{hr}$ after each daily drug treatment on E5-E10. Using curare doses similar to those used by Hory-Lee and Frank (1995), we were able to confirm that their nonparalytic doses failed to reduce motility levels when embryos were recorded $23 \mathrm{hr}$ after treatment (Fig. 1). However, when examined at earlier time points each day, all of the nonparalytic doses used in their study were found to reduce motility significantly for 6-12 hr or longer after each drug administration. We refer to these as "subparalytic" doses. Similar results were obtained using $\alpha$-BTX (data not shown) in which the highest dose $(100 \%)$ was $100 \mu \mathrm{g}$ on E5-E7, $75 \mu \mathrm{g}$ on E8 and E9, and $50 \mu \mathrm{g}$ on E10 and the lowest (truly nonparalytic) doses were 0.6 and $0.3 \%$ of the highest $(100 \%)$ dose. Only by reducing the doses of curare or $\alpha$-BTX lower than the lowest dose that was used by Hory-Lee and Frank (1995) were we able to obtain a truly nonparalytic dose that failed to reduce motility at any time point examined (Fig. 1). From these data, it is clear that only by assessing motility at several time points, not just at $23 \mathrm{hr}$ after treatment, is it possible to identify accurately a bona fide nonparalytic dose of curare or $\alpha$-BTX. Finally, the remaining movements in the paralyzed embryos, although in some instances of slightly lower amplitude, were nonetheless qualitatively similar to the movements of control embryos.

\section{Motoneuron survival after treatment with curare or $\alpha$-BTX}

Treatment of embryos with doses of curare that reduced motility for some or all of the $24 \mathrm{hr}$ period each day from E5 to E10 resulted in a dose-dependent rescue of MNs from naturally occurring cell death (Figs. 2, 3). By contrast, doses that were without any effect on motility failed to rescue MNs. This was true for each of the eight lumbar segments, including L4, the one segment in which MN counts were assessed by Hory-Lee and Frank (1995) (data not shown). Similar results were obtained with $\alpha$-BTX (data not shown). Therefore, we were unable to confirm their report that nonparalytic doses of these agents rescue MNs to the same extent as paralytic doses. In fact, we found that subparalytic doses that only reduced motility for 6-12 hr each day can still rescue MNs, although to a lesser extent than did completely paralytic doses. Furthermore, the number of degenerating (pyknotic) MNs on E7.5 was reduced in a dose-dependent manner by paralytic but not by nonparalytic doses of curare or $\alpha$-BTX [control (mean $\pm \mathrm{SD}$; per 1000 healthy MNs $), 23 \pm 3.5(n=4) ; 100 \% \alpha$-BTX, $6.1 \pm 2.0(n=$ 4); $10 \% \alpha$-BTX, $13 \pm 3.8(n=4)$; $0.6 \% \alpha$-BTX, $26.2 \pm 5.6(n=4)$; control vs $100 \%, p<0.001$; control vs $10 \%, p<0.01]$. From these data we conclude that paralytic and subparalytic doses of nicotinicblocking agents increase MN numbers by preventing cell degeneration and that reduced motility is correlated with the promotion of $\mathrm{MN}$ survival by these agents.

The chicken mutant $c n / c n$ has a defect in the muscle-specific $\alpha$-ryanodine ( $\alpha$-RyR) gene, resulting in the absence of excitationcontraction coupling, and these animals exhibit complete paralysis 

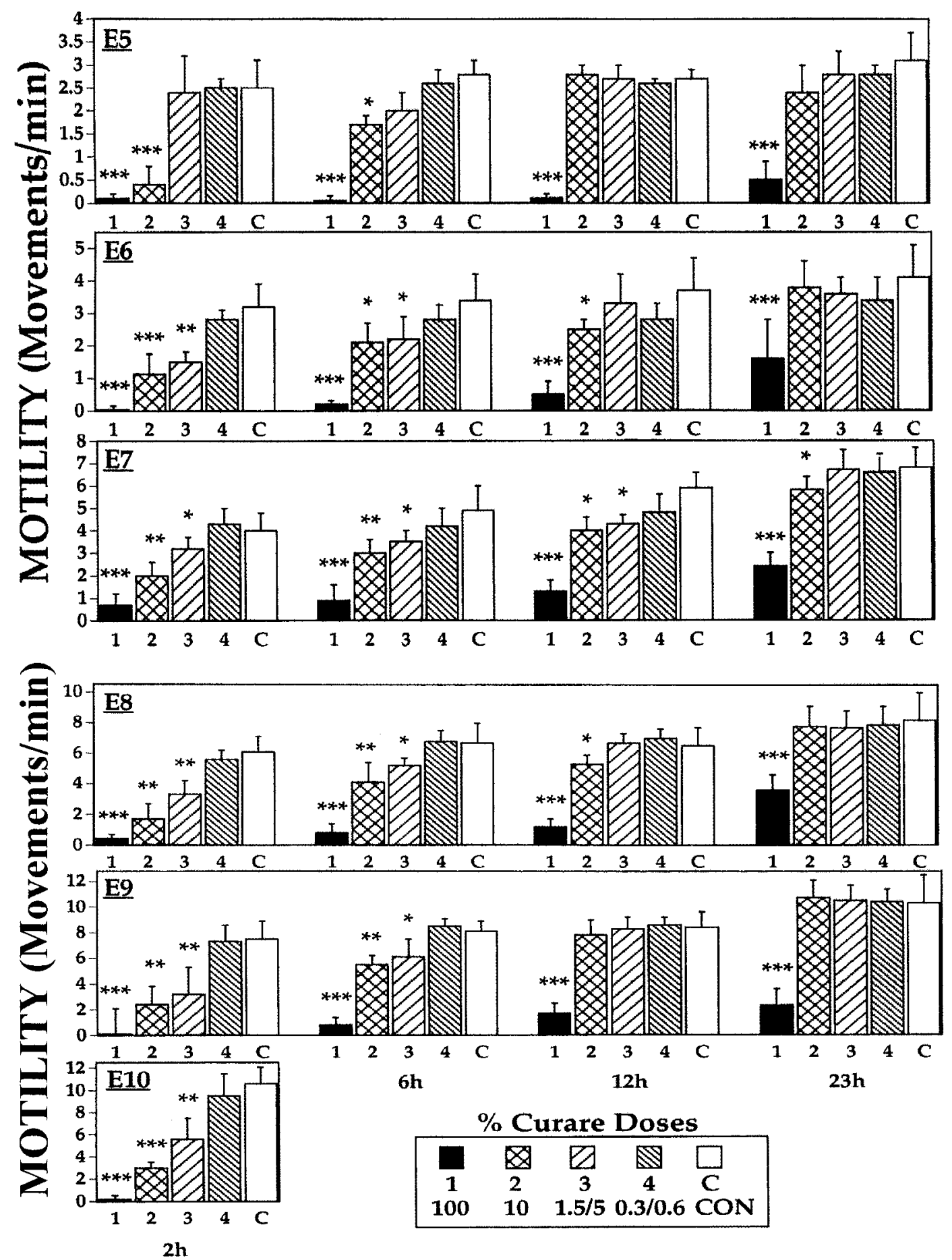

Figure 1. Neuromuscular activity (motility) expressed as movements per minute (mean \pm SD) at different times (2, 6, 12, and 23 hr) after daily administration of curare from E5 to E10. The doses $(1-4 ; 100-0.3 \%)$ are relative to the highest paralytic dose used (100\%). The actual 100\% doses used were $2 \mathrm{mg}$ on E5-E7, $3 \mathrm{mg}$ on E8 and E9, and $4 \mathrm{mg}$ on E10. Sample size (number of embryos) $=10-15$ per condition. ${ }^{*} p<0.05$; ${ }^{* *} p<0.01$; ${ }^{* * *} p<$ 0.001 (vs control; $t$ tests with Bonferroni correction). CON (C), Control.

during embryogenesis. The $\alpha$-RyR acts as a sarcoplasm reticulumspecific calcium release channel receptor that is only present in skeletal muscle. Similar to embryos paralyzed by curare or $\alpha$-BTX, $c n / c n$ embryos exhibit increased MN survival (Oppenheim et al., 1997). However, despite the apparent total paralysis, MN survival is $15-20 \%$ less in $\mathrm{cn} / \mathrm{cn}$ embryos than in control (nonmutant) curare- or $\alpha$-BTX-treated embryos. Therefore, we examined whether curare or $\alpha$-BTX treatment would further increase MN survival in $c n / c n$ embryos. In fact, both agents were able to promote MN survival further by $\sim 20 \%$ (Fig. 4; curare data not shown).
Although the most plausible interpretation of this finding is that the additional rescue effect of curare and $\alpha$-BTX is mediated centrally via neuronal nAChRs, other possibilities cannot be excluded (see Discussion).

\section{Intramuscular nerve branching and synaptogenesis after activity blockade}

Several previous studies have reported that chronic treatment of chick embryos with curare between E5 and E10 results in increased muscle innervation as assessed by nerve branching and synapse 

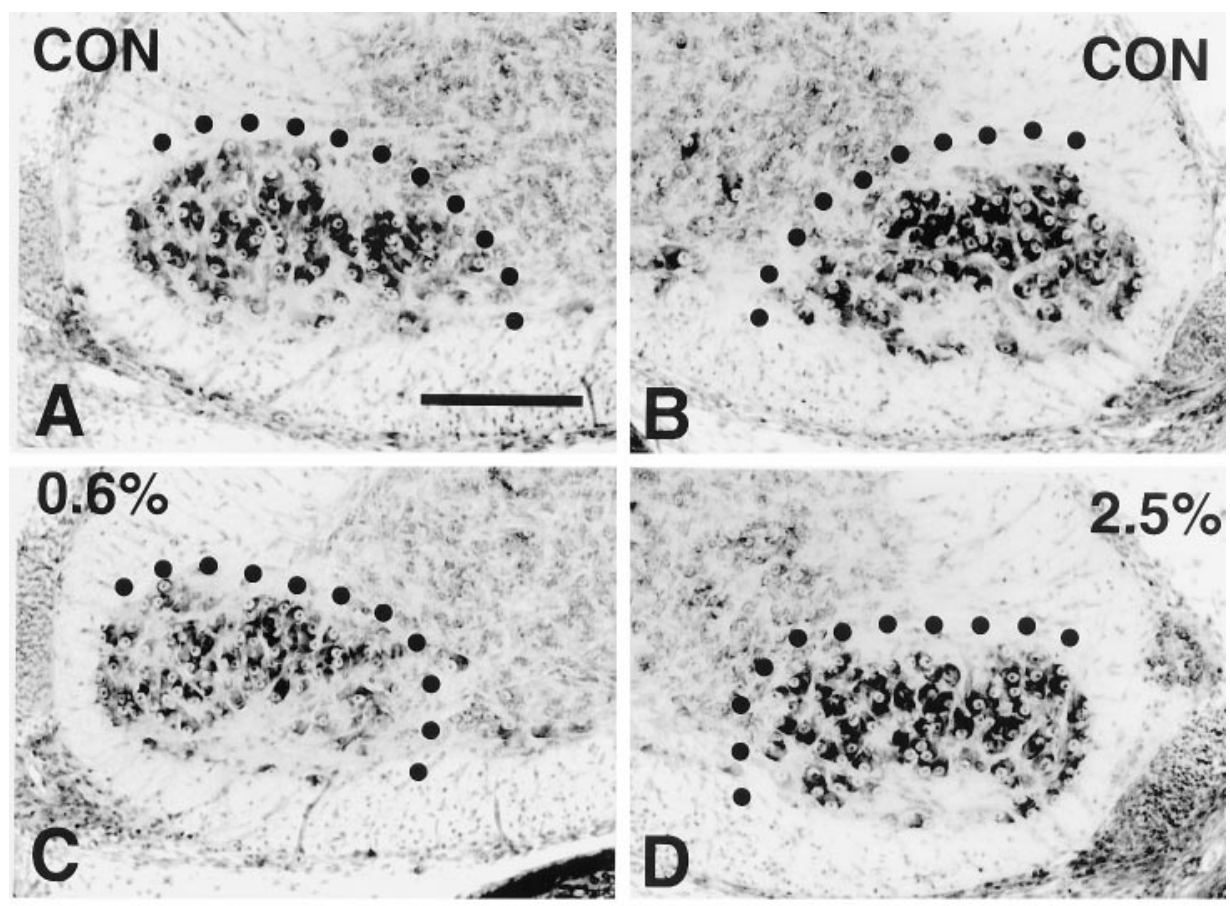

Figure 2. Transverse sections through the lumbar ventral horn on E10.5 of embryos treated with different doses of curare $(C-F)$ from E6 to E10 versus control embryos $(A, B)$ treated with saline. All sections are from a region exactly midway through the L3 segment as defined by the adjacent dorsal root ganglion. Scale bar, 150 $\mu \mathrm{m}$. CON, Control.
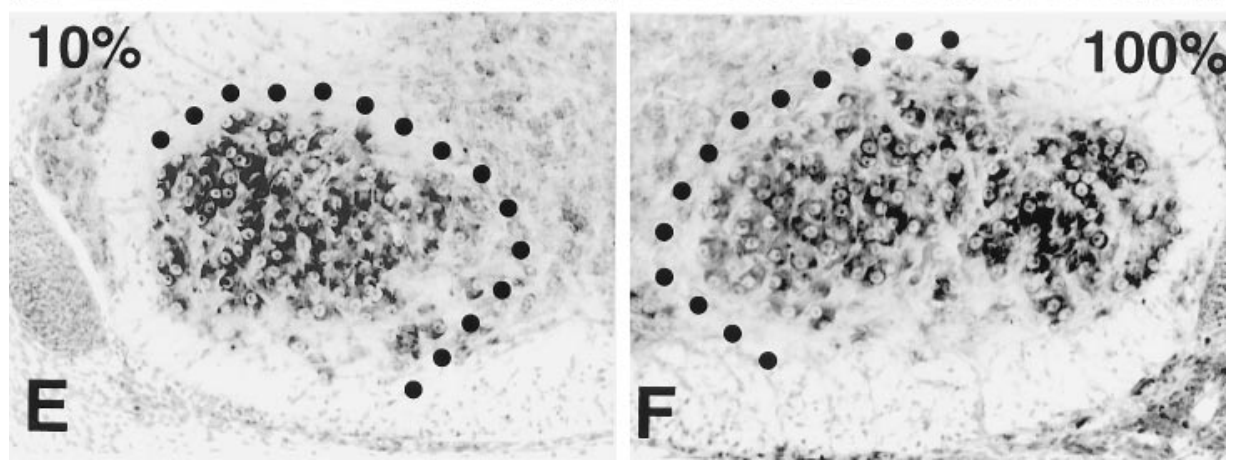

formation (Pittman and Oppenheim, 1979; Oppenheim and ChuWang, 1983; Oppenheim et al., 1989; Dahm and Landmesser, 1991; Fournier LeRay et al., 1993; D’Costa et al., 1998; Usiak and Landmesser, 1999). Because these changes occur at the very onset of the normal cell death period (Dahm and Landmesser, 1988, 1991), it was postulated that they are likely to be the cause rather than the effect of the increased MN survival (Oppenheim, 1989; Landmesser, 1992). By contrast, in the study by Hory-Lee and Frank (1995), they report that MN survival after treatment with curare or $\alpha$-BTX is quantitatively unrelated to nerve branching.

Because we have failed to confirm the report of Hory-Lee and Frank (1995) regarding the effects of nonparalytic doses of curare and $\alpha$-BTX on motility and MN survival, we believed it was important also to examine axon branching and synaptogenesis after treatment with paralytic, subparalytic, and nonparalytic doses of these agents. As summarized in Figure 5, we found that paralytic and subparalytic doses of curare, even doses that only partially reduce motility, increased branching and synapse formation in two hindlimb muscles on E9, whereas nonparalytic doses were without effect on either measure. Similar results were obtained with $\alpha$-BTX (data not shown). These data are consistent with the suggestion that intramuscular nerve branching and synapse formation may be causally related to the increased MN survival after treatment with curare or $\alpha$-BTX.

\section{Motility and MN survival after treatment with other nicotinic-blocking agents}

As described in more detail below, nAChRs are known to be expressed on neurons in the CNS (Sargent, 1993; Role and Berg, 1996; Lindstrom, 1997). Furthermore, both curare and $\alpha$-BTX can bind to nAChRs in the chicken CNS (Renshaw et al., 1993) and perturb the physiological activity of MNs (Landmesser and Szente, 1986; Milner and Landmesser, 1999; Usiak and Landmesser, 1999). Collectively, these data raise the possibility that the effects of nicotinic-blocking agents such as curare and $\alpha$-BTX in promoting MN survival in ovo may be at least partly via their actions on neuronal and not on muscle nAChRs. The experiment involving $c n / c n$ embryos (see above) could also be interpreted as being consistent with this possibility.

To examine this, we have used a number of drugs and toxins that at the appropriate dose act as antagonists of specific nAChR subunits expressed in either muscle or neurons. These agents and their subunit specificity include the following: MLA $(\alpha 7)$, decamethonium (Dec; $\alpha 1$ ), IMI ( $\alpha 7$ and $\alpha 9)$, MI $(\alpha 1)$, GI $(\alpha 1)$, MII $(\alpha 3 \beta 2)$, EIVA $(\alpha 1)$, AuIB $(\alpha 3 \beta 4)$, and $\mathrm{DH} \beta \mathrm{E}(\alpha 4 \beta 2$ more than other subtypes).

As summarized in Table 1, with the exception of $\mathrm{DH} \beta \mathrm{E}$ and AuIB, only those agents with specificity for the $\alpha 1$ muscle-type subunit $\mathrm{nAChR}$ rescued $\mathrm{MNs}$, whereas the other agents were ineffective. Furthermore, combined treatment with EIVA $(\alpha 1$; muscle-type antagonist) and MLA ( $\alpha 7$; neuronal-type antagonist) was no more effective than treatment with EIVA alone in promoting MN survival. This suggests that the simultaneous blockade of both muscle- and neuronal (at least $\alpha 7$ )-type nAChRs is not required for promoting $\mathrm{MN}$ survival. Additionally, only those agents that rescued MNs also significantly reduced motility levels on E7-E10 (Table 1) and increased axonal branching (data not shown). Treatment with the highest dose of both $\mathrm{DH} \beta \mathrm{E}(100 \mu \mathrm{M})$ and AuIB $(250 \mu \mathrm{M})$ reduced motility by $20-30 \%$ on E7-E10 but 


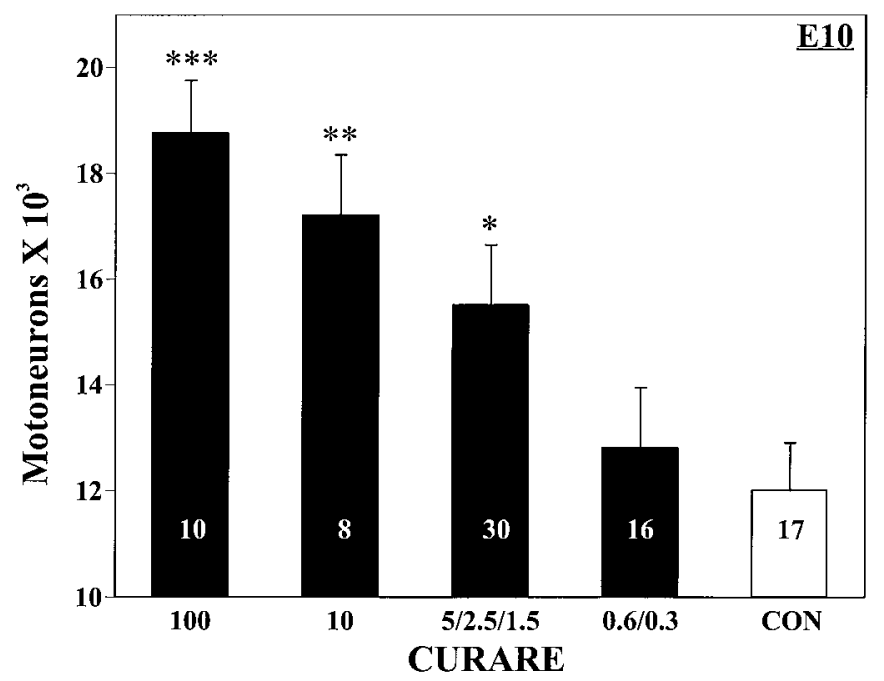

Figure 3. The number of lumbar motoneurons (mean \pm SD) on E10 after treatment with different doses of curare from E5 to E10. Numbers in bars are sample sizes (numbers of embryos). ${ }^{*} p<0.02 ;{ }^{*} p<0.01{ }^{* * *} p<0.001$ (vs control; $t$ tests with Bonferroni correction). $C O N$, Control.

had only a modest rescue effect compared with subparalytic doses of curare or $\alpha$-BTX that reduced motility to approximately the same extent (see Fig. 3). In contrast, with lower doses, neither $\mathrm{DH} \beta \mathrm{E}(100-200 \mathrm{nM})$ nor AuIB $(0.5 \mu \mathrm{M})$ had an effect on motility or MN numbers (data not shown). The effective dose of decamethonium used here was approximately double the amount used in a previous study in which no rescue effect was observed (Oppenheim et al., 1989). Collectively, these results are consistent with the argument that the rescue of MNs by nicotinic-blocking agents is mediated primarily by the inhibition of muscle-type nAChRs. Even combined treatment with antagonists that act on both muscle- and neuronal-type receptors ( $\alpha 1$ and $\alpha 7$ ) was no more effective than treatment with muscle-type antagonists alone.

\section{DISCUSSION}

\section{Neuromuscular activity, MN survival, and muscle innervation}

Since our first report $>20$ years ago (Pittman and Oppenheim, 1978), a number of laboratories have independently confirmed our original observation that reductions in neuromuscular activity,

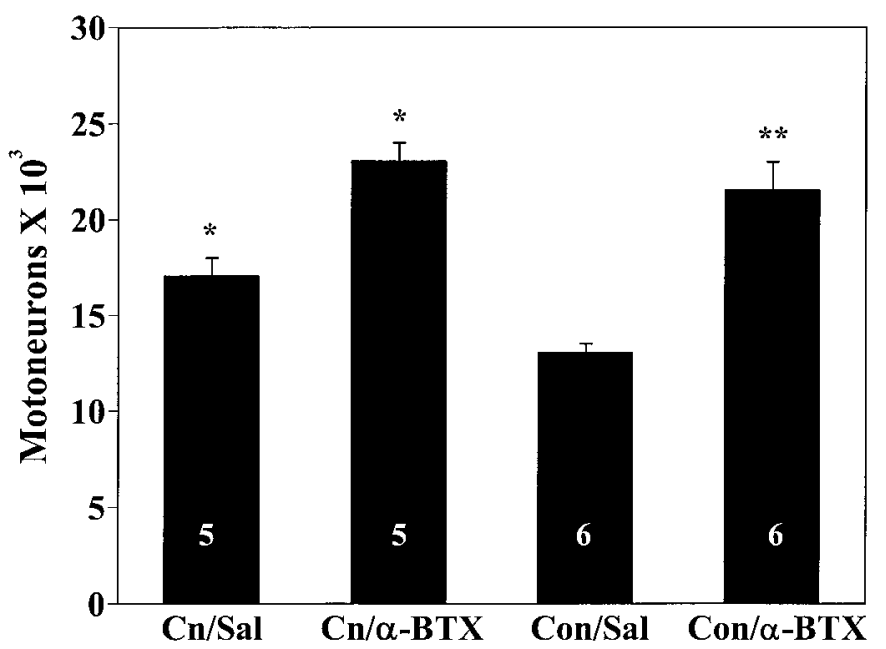

Figure 4. Motoneuron numbers (mean \pm SD) on E10 in mutant crooked neck $(\mathrm{Cn})$ and control (Con) embryos after treatment with $\alpha$-BTX $(\alpha-B T X)$ or saline (Sal). Numbers in bars indicate sample size (number of embryos) ${ }^{*} p<0.01, \mathrm{Cn} / \mathrm{Sal}$ versus $\mathrm{Con} / \mathrm{Sal}$ or $\mathrm{Cn} / \alpha-\mathrm{BTX}$ versus $\mathrm{Cn} / \mathrm{Sal}$; **p $<0.001$, Con $/ \alpha-B T X$ versus Con/Sal ( $t$ tests).
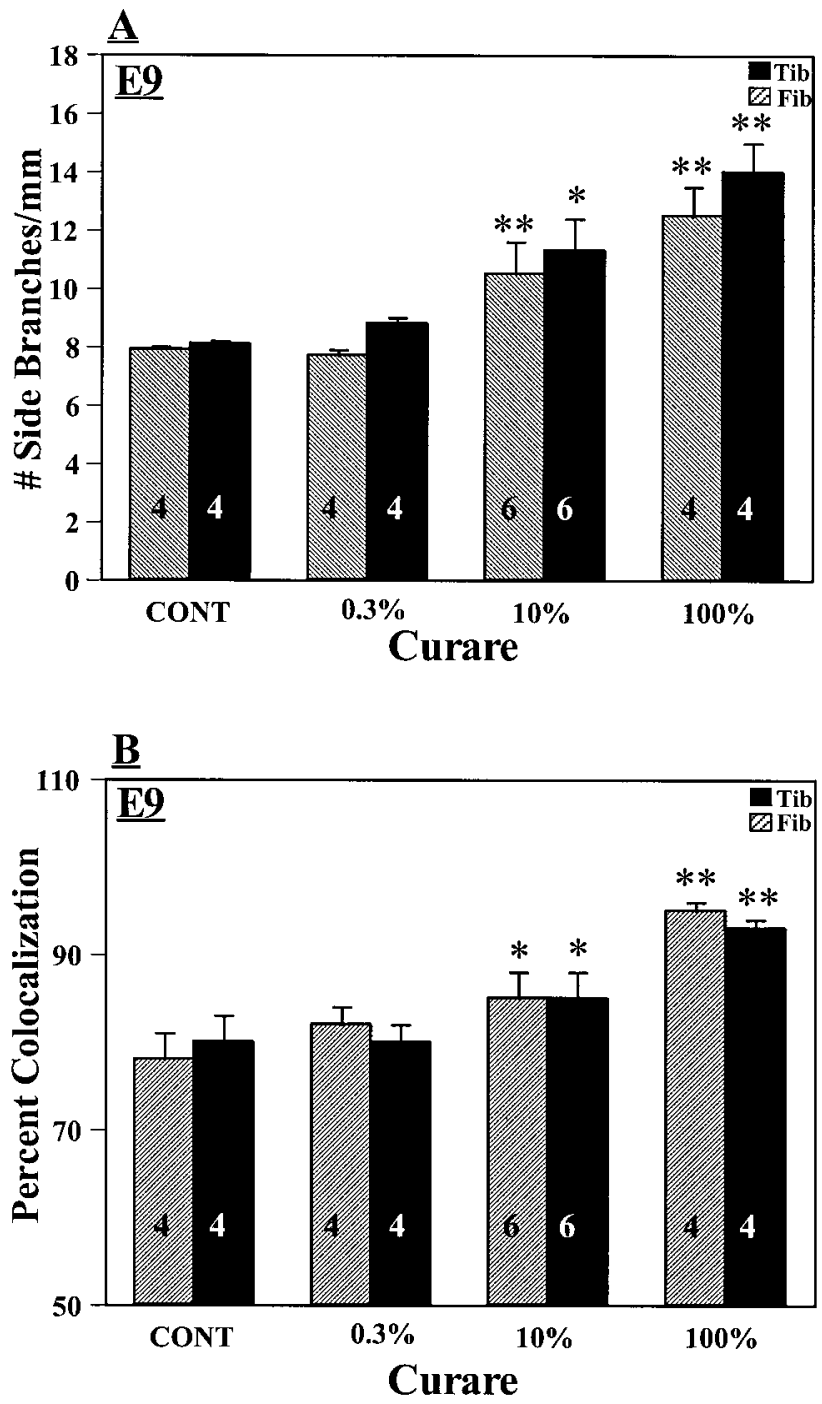

Figure 5. The number of side branches per millimeter of nerve length and synapses (percent colocalization; mean $\pm \mathrm{SD}$ ) on E9 in the iliotibialis $(T i b)$ and iliofibularis (Fib) muscles of control (CONT) embryos and embryos treated daily with paralytic $(100 \%)$, subparalytic $(10 \%)$, or nonparalytic $(0.3 \%)$ doses of curare from E5 to E8. Numbers in bars indicate sample size (number of embryos). ${ }^{*} p<0.01$ versus $C O N T$; $* * p<0.001$ versus CONT $(t$ tests).

after treatment with exogenous nicotine receptor-blocking agents applied during, but not before or after, the period of MN PCD, prevent the normal degeneration of these cells (Oppenheim, 1987; Landmesser, 1992). Because the excess rescued MNs die a delayed death after treatment is stopped and neuromuscular activity recovers and because experimentally induced hyperactivity of muscle (i.e., direct electrical stimulation of hindlimb musculature) increases the rate of PCD (Oppenheim and Nunéz, 1982), it has generally been assumed that neuromuscular (or muscle) activity is a critical factor in these studies and that such activity is inversely related to MN survival. Independent evidence consistent with this assumption is available from chicken and mouse paralytic genetic mutants in which muscle activity per se is absent, because of defects in excitation-contraction coupling, but MN activity centrally is normal. These embryos also exhibit increased MN survival and hyperinnervation (e.g., increased intramuscular axon branching) of muscle (Oppenheim et al., 1986, 1997). Taken together, these various lines of evidence have led to the suggestion that muscle activity plays an important role in regulating normal MN survival and that treatment of embryos with nicotinic-blocking agents promotes survival by perturbing muscle activity, via their blockade of muscle nAChRs. 
Table 1. Motoneuron numbers (mean \pm SD) in vivo on E10 after daily treatment with nAChR-blocking agents from E6 to E9

\begin{tabular}{|c|c|c|c|c|c|c|c|c|c|c|c|}
\hline & Cont & MLA & EIVA $^{a}$ & $\mathrm{MLA} \mathrm{EIVA}^{a}$ & $\operatorname{Dec}^{a}$ & IM I & $\mathrm{MI}^{a}$ & $\mathrm{GI}^{a}$ & MII & $\mathrm{DH} \beta \mathrm{E}^{\mathrm{b}, \mathrm{c}}$ & $\mathrm{AuIB}^{\mathrm{b}, \mathrm{c}}$ \\
\hline Subunit specificity & - & $\alpha 7$ & $\alpha 1$ & $\alpha 7 / \alpha 1$ & $\alpha 1$ & $\alpha 7 / \alpha 9$ & $\alpha 1$ & $\alpha 1$ & $\alpha 3 \beta 2$ & $\alpha 4 \beta 2$ & $\alpha 3 \beta 4$ \\
\hline Mean & 12,317 & 12,110 & 16,575 & 15,828 & 17,931 & 13,053 & 16,415 & 15,630 & 12,025 & 13,784 & 14,150 \\
\hline $\mathrm{SD}$ & 509 & 490 & 567 & 516 & 609 & 663 & 472 & 510 & 416 & 556 & 816 \\
\hline$n$ & 15 & 15 & 6 & 6 & 6 & 6 & 8 & 7 & 8 & 10 & 4 \\
\hline
\end{tabular}

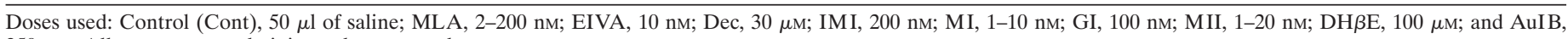

$250 \mu \mathrm{M}$. All agents were administered once per day.

${ }^{a} p<0.001$ vs Cont.

${ }^{b} p<0.05$ vs Cont $(t$ test $)$.

${ }^{c}$ Doses of 100-200 nм DH $\beta$ E and $0.5 \mu \mathrm{M}$ AuIB were ineffective (data not shown).

Significant $(p<0.01$ to $p<0.005)$ reductions in motility of $60-89 \%$ were observed on E7-E10 after treatment with EIVA, MLA/EIVA, Dec, MI, and GI.

This conclusion was called into question by the recent report that MN survival and muscle innervation are apparently unrelated to changes in neuromuscular activity after treatment with nicotinicblocking agents (Hory-Lee and Frank, 1995). In the experiments reported here, however, we have been unsuccessful in repeating the findings of Hory-Lee and Frank (1995). We find that doses of curare or $\alpha$-BTX reported by them to be nonparalytic, in fact, significantly reduced neuromuscular activity for several hours each day. Although the partial rescue of MNs by activity blockade that lasts only for several hours each day (subparalytic) is unexpected, our assay for activity (motility) is crude, and it is possible that more subtle physiological changes may persist for even longer and affect nerve branching, synapse formation, and MN survival (see Usiak and Landmesser, 1999).

In searching for an explanation for the discrepancy between these data and those of Hory-Lee and Frank (1995), we have considered several possibilities. First, Hory-Lee and Frank (1995) only counted MNs in the L4 segment of the spinal cord, whereas we have included MNs in all (L1-L8) lumbar segments. However, we find the same results (i.e., no increase in MN survival with nonparalytic doses of curare or $\alpha$-BTX) in each of the eight lumbar segments, including L4. Although it is also possible that the method of motility recording, the strain of chickens used, drug/toxin sources, etc., differed in the two studies, in the final analysis none of these potential differences can account for the fact that, in contrast to Hory-Lee and Frank, we find (1) that bona fide nonparalytic doses of curare or $\alpha$-BTX fail to promote MN survival or (2) that paralytic or subparalytic doses promote survival and increase branching in a dose-dependent manner.

One significant difference between the two studies is the timing of motility recordings after drug treatment each day. With the exception of one age (E9), out of the $7 \mathrm{~d}$ of treatment, Hory-Lee and Frank only report recording motility once each day, $\sim 20 \mathrm{hr}$ after drug administration. Although they failed to observe a decrease in motility $2 \mathrm{hr}$ after treatment with a nonparalytic dose on E9, by not recording motility more often each day they may have nonetheless missed the transient reductions in motility at other ages that we have found to begin reliably within $\sim 2 \mathrm{hr}$ after treatment and to continue for 6-12 hr or longer depending on the dose and embryonic age. Only by using doses one to two orders of magnitude lower than the lowest dose used by them were we able to identify truly nonparalytic doses at all recording times. Interestingly, these investigators have now independently confirmed that subparalytic doses of curare do, in fact, reduce motility and rescue MNs in a dose-dependent manner (P. Pugh and E. Frank, personal communication). From these data, we conclude that there is a dose-dependent relationship between MN survival, muscle innervation, and neuromuscular activity and that bona fide nonparalytic doses of the nicotinic-blocking agents curare and $\alpha$-BTX are ineffective in promoting MN survival or muscle innervation in the chick embryo.

\section{Muscle- and neuronal-type nAChRs and MN survival}

Despite our failure to replicate the effects of nonparalytic doses of curare or $\alpha$-BTX reported by Hory-Lee and Frank (1995), this failure does not exclude the possibility that these agents may nonetheless rescue MNs by acting via neuronal nAChRs on the cell body, dendrites, and axon or presynaptically at the MN terminal (Posada and Clarke, 1999). Neuronal nAChRs are known to exist in the developing avian and human CNS (Role and Berg, 1996; Lindstrom, 1997; Hellstrom-Lindahl et al., 1998; Kaneko et al., 1998), and previous binding studies using radiolabeled nAChR ligands report significant binding in the chick embryo and human fetal spinal cord (Renshaw et al., 1993; Renshaw, 1994; HellstromLindahl et al., 1998). Nine of the 10 vertebrate genes encoding neuronal AChR subunits $(\alpha 2-\alpha 7$ and $\beta 2-\beta 4)$ have been isolated from chick brain (Role and Berg, 1996), and using reverse transcription-PCR and immunocytochemistry, we have confirmed the expression of several neuronal-type nAChR subunits in developing chick spinal cord (Keiger et al., 1998).

Both curare and $\alpha$-BTX have access to the embryonic CNS and have been shown to perturb directly spinal MN electrical activity in vivo (Landmesser and Szente, 1986; Usiak and Landmesser, 1999). These results raise the possibility that nicotinic-blocking agents may rescue MNs from cell death in vivo by perturbing nAChRmediated spinal cord circuits that drive MN activity. Although depolarization can promote the survival of dissociated avian and mammalian MNs in vitro (Lloyd et al., 1994; Hanson et al., 1998; Soler et al., 1998), cultured MNs can nonetheless survive in the presence of muscle extract (MEX) without depolarization. Furthermore, increasing the amount of synaptic activity (and depolarization) in ovo by direct chronic spinal cord electrical stimulation during the period of cell death does not affect MN survival (Fournier LeRay et al., 1993). Nicotinic-blocking agents also fail to promote the survival of cultured MNs (Hory-Lee and Frank, 1995; Oppenheim et al., 1996) and are unable to prevent MN death in ovo in the absence of peripheral muscle targets (Pittman and Oppenheim, 1979; Hory-Lee and Frank, 1995; Calderó et al., 1998). These data argue strongly against the role of intrinsic spinal cord activity, per se, or blockade of neuronal nAChRs alone in regulating MN survival in the chick embryo.

In a further attempt to address the issue of central versus peripheral actions of nicotinic-blocking agents, we have used a number of nAChR-specific antagonists that at the appropriate doses are selective for either muscle- or neuronal-type nAChR subunits (Johnson et al., 1995; Cartier et al., 1996; Jacobsen et al., 1997; Luo et al., 1998). The results clearly indicate that with the exception of $\mathrm{DH} \beta \mathrm{E}$ and $\mathrm{AuIB}$, only those agents selective for the muscle-type $\alpha 1 \mathrm{nAChR}$ subunit (i.e., MI, GI, EIVA, and decamethonium), but not those specific for the neuronal-type $\alpha 7$ (MLA and IMI), $\alpha 9$ (IMI), or $\alpha 3 \beta 2$ (MII) nAChR subunits, reduce motility and promote $\mathrm{MN}$ survival in vivo. Additionally, the absence of the predominant $\alpha$-BTX-binding neuronal $\alpha 7$ subunit in mice after genetic deletion (Orr-Urtreger et al., 1997) is reported 
to be without effect on MN survival (E. Frank, personal communication), and spinal cord development also occurs normally in mice deficient in the neuronal $\alpha 3$ subunit (Xu et al., 1999). The effects of $\mathrm{DH} \beta \mathrm{E}$ and AuIB on MN survival are potentially interesting and suggest that neuronal nAChRs of the $\alpha 4 \beta 2$ or $\alpha 3 \beta 4$ subtype could be involved in the rescue effects of curare. After $\alpha 7$-type receptors, the $\alpha 4 \beta 2$-type receptor is the second most abundant neuronal $\mathrm{nAChR}$ in developing chicken brain (Conroy and Berg, 1998). However, because the $\alpha 4$ subunit is also expressed in chick embryo skeletal muscle ( $\beta 2$ has not been examined) (Corriveau et al., 1995) and because the rescue of MNs by $\mathrm{DH} \beta \mathrm{E}$ only occurred at high doses that were subparalytic (i.e., lower doses, 100-200 nM, did not affect motility or rescue MNs), it is possible that $\mathrm{DH} \beta \mathrm{E}$ is acting nonspecifically or even directly on muscle nAChRs. Similarly, doses of AuIB that rescued MNs (250 $\mu \mathrm{M})$ were also subparalytic, whereas lower doses $(0.5 \mu \mathrm{M})$ failed to rescue MNs or affect motility; and similar to the $\alpha 4$ subunit, the $\beta 4$ subunit is also expressed in chick embryo muscle (Corriveau et al., 1995). Blockade of either $\beta 2$ or $\alpha 3$ by the $\alpha 3 \beta 2$-specific snail cone antagonist (MII) also did not rescue MNs in ovo. In view of all of the other evidence presented here in support of the role of muscletype nAChRs in rescuing MNs after activity blockade, we favor the idea that the effects of high doses of $\mathrm{DH} \beta \mathrm{E}$ and AuIB likely reflect a peripheral site of action. Although we have attempted to exclude the involvement of many of the other most plausible neuronal nAChR subunits, including $\alpha 7$, in mediating the in vivo effects of curare and $\alpha$-BTX on MN survival, it remains a possibility that one or more of the neuronal subunits not examined by us (e.g., $\alpha 2, \alpha 6$, or $\alpha 5$ ) could mediate survival by a central site of action (Zoli et al., 1995). Additionally, although we have used doses of the various antagonists that are reported to exhibit specificity for particular neuronal- or muscle-type nAChR subtypes (Johnson et al., 1995; Cartier et al., 1996; Jacobsen et al., 1997; Luo et al., 1998), these doses have been primarily established on the basis of studies of mammalian cells and therefore may in some cases have less specificity for avian receptors.

In a recent study, Usiak and Landmesser (1999) have reported that in ovo treatment with the $\mathrm{GABA}_{\mathrm{A}}$ receptor agonist muscimol indirectly blocks neuromuscular activity (motility) by suppressing $\mathrm{MN}$ activity centrally but fails to rescue MNs. Furthermore, in agreement with our present results, they find that paralytic and subparalytic doses of curare promote MN survival and increase intramuscular nerve branching. An interesting and novel finding in their study was that curare directly blocked the neuromuscular junction peripherally but at some stages also increased the spontaneous bursting activity of MNs centrally, whereas muscimol only indirectly blocked neuromuscular activity by suppressing spontaneous MN activity centrally. When administered together with curare, muscimol was reported to block the rescue effects of curare and also to reduce curare's effects on intramuscular nerve branching. From these results, Usiak and Landmesser (1999) postulate that target (muscle) inactivity needs to be coupled with active MNs to prevent cell death. Although differing in some important respects from the proposal of Hory-Lee and Frank (1995), their scheme is similar in that central effects of nicotinic-blocking agents are thought to be required for the rescue of MNs. In a beginning attempt to examine this idea further, we first attempted to replicate the effects of muscimol reported by Usiak and Landmesser (1999). In contrast to their report, however, we find that muscimol promotes MN survival to the same extent as curare and that muscimol potentiates rather than blocks the effects of curare on MN survival (Ayala et al., 2000).

If the activation of MNs by curare during the cell death period is critical for promoting MN survival, then direct electrical stimulation of the spinal cord of curare-treated embryos might be expected to promote MN survival further, but as we have reported previously (Fournier LeRay et al., 1993), it does not. These findings seem to be inconsistent with the idea that only active MNs can respond, or that they respond better, to survival signals (e.g., trophic factors) associated with neuromuscular blockade. Finally, our observation that treatment with MEX rescues the same number of MNs in vivo regardless of the presence or absence of curare (Calderó et al., 1998) also seems inconsistent with the prediction of Usiak and Landmesser (1999) that active MNs are more responsive to trophic factors.

The chicken paralytic mutant $c n$ provides one possible way to help distinguish between the role of muscle versus neuronal nAChRs. Because the genetic mutation in these animals involving the loss of the $\alpha$-RyR calcium channel receptor and a failure of excitation-contraction coupling is expressed only in skeletal muscle and not in the spinal cord (Oppenheim et al., 1997), the paralysis-related increase in $\mathrm{MN}$ survival would seem not to be caused by a defect in neuronal calcium channels or by a central perturbation of MN activity but rather to be caused by the absence of muscle activity, per se. However, because we have found here that the significant (but not total) rescue of MNs in this mutant can be further increased by treatment with curare or $\alpha$-BTX, it is possible that this additional rescue effect is mediated by these agents acting centrally on neuronal nAChRs. An alternative explanation for the effects of curare or $\alpha$-BTX on the mutant embryos is that treatment with these nicotinic-blocking agents can somehow act to increase $\mathrm{MN}$ survival further via a peripheral action on muscle-specific nAChRs in the $c n$ mutant without having any obvious effects on motility or muscle activity in these already totally paralyzed embryos. For example, the CNS-mediated physiological effects of curare or $\alpha$-BTX in suppressing MN activity during most of the cell death period, as reported by Landmesser and Szente (1986) and Usiak and Landmesser (1999), may reduce the activation of muscle nAChRs by impairing the "spontaneous" release of acetylcholine from MN terminals, thereby affecting signal transduction and nerve-muscle interactions. Admittedly, however, we have no evidence that nicotinic-blocking agents can promote $\mathrm{MN}$ survival in this way in the mutant embryos. It is also possible that the mechanisms that mediate increased MN survival in curaretreated nonmutant embryos are fundamentally different from the actions of curare in the $\mathrm{cn}$ mutant.

In summary, we tend to favor the idea that the increased $\mathrm{MN}$ survival after curare or $\alpha$-BTX treatment in vivo is caused by reduced muscle activity that is mediated by the blockade of muscletype nAChRs, resulting in increased access of MNs to musclederived or (peripheral nerve-derived) trophic agents according to the access hypothesis (Oppenheim, 1989; Landmesser, 1992; D'Costa et al., 1998). However, some of our own evidence presented here (e.g., the increased rescue of MNs by curare in the $c n$ mutant and the effects of high doses of $\mathrm{DH} \beta \mathrm{E}$ and $\mathrm{AuIB}$ ) are also consistent with the possibility that a central action of nicotinicblocking agents may play at least a contributory role in the rescue of MNs. Although further studies will be necessary to resolve this issue, it is now quite clear that activity, whether in the form of muscle contractions, $\mathrm{MN}$ activity, or both, is fundamentally involved in the regulation of MN survival during development (Pittman and Oppenheim, 1978; Usiak and Landmesser, 1999) (present results). Accordingly, previous claims to the contrary (Hory-Lee and Frank, 1995) are not correct.

\section{REFERENCES}

Ayala V, Calderó J, Cuitat D, Esquerda J, Oppenheim RW, Prevette D, Ribera J (2000) Blockade of neuromuscular activity by the GABA agonist muscimol promotes the survival of motoneurons in the chick embryo. Soc Neurosci Abstr 26, in press.

Bloch-Gallego E, Huchet ME, M'Hami H, Xie FK, Tanaka H, Henderson CE (1991) Survival in vitro of motoneurons identified or purified by novel antibody-based methods is selectively enhanced by muscle-derived factors. Development 111:221-232.

Calderó J, Prevette D, Mei X, Oakley RA, Li L, Milligan C, Houenou L, Burek M, Oppenheim RW (1998) Peripheral target regulation of the development and survival of spinal sensory and motor neurons in the chick embryo. J Neurosci 18:356-370.

Cartier GE, Yoshikami D, Gray WR, Luo S, Olivera BM, McIntosh JM (1996) A new $\alpha$-conotoxin which targets $\alpha 3 \beta 2$ nicotinic acetylcholine receptors. J Biol Chem 271:7522-7528.

Chu-Wang IW, Oppenheim RW (1978) Cell death of motoneurons in the chick embryo spinal cord. J Comp Neurol 177:33-86. 
Clarke PGH, Oppenheim RW (1995) Neuron death in vertebrate development: in vivo methods. In: Methods in cell biology, Vol 46, Cell death (Schwartz LM, Osborne BA, eds), pp 277-321. New York: Academic.

Conroy WG, Berg DK (1998) Nicotinic receptor subtypes in the developing chick brain: appearance of a species containing the $\alpha 4, \beta 2$ and $\alpha 5$ gene products. Mol Pharmacol 53:392-401.

Corriveau RA, Romano SJ, Conroy WG, Oliva L, Berg DK (1995) Expression of neuronal acetylcholine receptor genes in vertebrate skeletal muscle during development. J Neurosci 15:1372-1383.

Dahm L, Landmesser L (1988) The regulation of intramuscular nerve branching during normal development and following activity blockade. Dev Biol 130:621-644.

Dahm L, Landmesser L (1991) The regulation of synaptogenesis during normal development and following activity blockade. J Neurosci 11:238-255.

D'Costa A, Prevette D, Houenou LJ, Wang S, Zackenfels K, Rohrer H, Zapf J, Caroni P, Oppenheim RW (1998) Mechanisms of insulin-like growth factor regulation of programmed cell death of developing avian motoneurons. J Neurobiol 36:379-394.

Dohrmann U, Edgar D, Sendtner M, Thoenen H (1986) Muscle-derived factors that support survival and promote fiber outgrowth from embryonic chick spinal motor neurons in culture. Dev Biol 118:209-221.

Fournier LeRay C, Prevette D, Oppenheim RW, Fontaine-Perus J (1993) Interactions between spinal cord stimulation and activity blockade in the regulation of synaptogenesis and motoneuron survival in the chick embryo. J Neurobiol 24:1142-1156.

Hamburger V (1975) Cell death in the development of the lateral motor column of the chick embryo. J Comp Neurol 160:535-546.

Hamburger V, Hamilton HL (1951) A series of normal stages in the development of the chick embryo. J Morphol 88:49-92.

Hanson MG, Shiliang S, Wiemelt AP, McMorris FA, Barres BA (1998) Cyclic AMP elevation is sufficient to promote the survival of spinal motor neurons in vitro. J Neurosci 18:7361-7371.

Hellstrom-Lindahl E, Gorbounova O, Seiger A, Mousavi M, Nordberg A (1998) Regional distribution of nicotinic receptors during prenatal development of human brain and spinal cord. Dev Brain Res 108:147-160.

Hory-Lee F, Frank E (1995) The nicotinic blocking agents D-tubocurare and $\alpha$-bungarotoxin save motoneurons from naturally occurring death in the absence of neuromuscular blockade. J Neurosci 15:6453-6460.

Houenou LJ, McManaman JL, Prevette D, Oppenheim RW (1991) Regulation of putative muscle-derived neurotrophic factors by muscle activity and innervation: in vivo and in vitro studies. J Neurosci 11:2829-2837.

Jacobsen R, Yoshikami D, Ellison M, Martinez J, Gray WR, Cartier GE, Shon K-J, Groebe DR, Abramson SN, Olivera BM, McIntosh JM (1997) Differential targeting of nicotinic acetylcholine receptors by novel $\alpha \mathrm{A}$ conotoxins. J Biol Chem 272:22531-22537.

Johnson DS, Martinez J, Elgoyhen AB, Heinemann SF, McIntosh JM (1995) $\alpha$-Conotoxin ImI exhibits sub-type specific nicotinic acetylcholine receptor blockade: preferential inhibition of homomeric $\alpha 7$ and $\alpha 9$ receptors. Mol Pharmacol 48:194-199.

Kaneko WM, Britto LRG, Lindstrom JM, Karten JM (1998) Distribution of the $\alpha 7$ nicotinic acetylcholine receptor subunit in the developing chick cerebellum. Dev Brain Res 105:141-145.

Keiger CJ, Prevette D, Oppenheim RW (1998) Developmental expression of neuronal and muscle nicotinic receptor subunits in chick spinal cord and limb-bud muscle. Soc Neurosci Abstr 24:793.

Landmesser L (1992) The relationship of intramuscular nerve branching and synaptogenesis to motoneuron survival. J Neurobiol 23:1131-1139.

Landmesser L, Szente M (1986) Activation pattern of embryonic chick hind-limb muscles following blockade of activity and motoneuron cell death. J Physiol (Lond) 380:157-174.

Lindstrom J (1997) Nicotinic acetylcholine receptors in health and disease. Mol Neurobiol 15:193-222.

Lloyd ED, Lo AC, Oppenheim RW, Houenou LJ (1994) Survival effects of depolarization on chick motoneurons in vitro. Soc Neurosci Abstr 20:683.

Luo S, Kulak JM, Cartier GE, Jacobsen RB, Yoshikami D, Olivera BM, McIntosh JM (1998) $\alpha$-Conotoxin AuIB selectively blocks $\alpha 3 \beta 4$ nicotinic acetylcholine receptors and nicotine-evoked norepinephrine release. J Neurosci 18:8571-8579.

Milner D, Landmesser LT (1999) Cholinergic and GABAergic inputs drive patterned spontaneous motoneuron activity before target contact. J Neurosci 19:3007-3022.

Oppenheim RW (1975) The role of supraspinal input in embryonic motility. J Comp Neurol 160:37-50.

Oppenheim RW (1987) Muscle activity and motor neuron death in the spinal cord of the chick embryo. In: Selective neuronal death (O'Connor $\mathrm{M}$, ed), pp 96-112. London: Ciba.

Oppenheim RW (1989) The neurotrophic theory and naturally occurring motoneuron death. Trends Neurosci 12:252-255.

Oppenheim RW (1991) Cell death during development of the nervous system. Annu Rev Neurosci 14:453-501.

Oppenheim RW (1996) Neurotrophic survival molecules for motoneurons; an embarrassment of riches. Neuron 17:195-197.
Oppenheim RW, Chu-Wang IW (1983) Aspects of naturally occurring motoneuron death in the chick spinal cord during embryonic development. In: Nerve-muscle interactions (Burnstock G, ed), pp 57-107. Amsterdam: Elsevier.

Oppenheim RW, Nunéz R (1982) Electrical stimulation of hindlimb increases neuronal cell death in the chick embryo. Nature 295:57-59.

Oppenheim RW, Chu-Wang IW, Maderdrut JL (1978) Cell death of motoneurons in the chick embryo spinal cord. J Comp Neurol 177:87-112.

Oppenheim RW, Houenou L, Pincon-Raymond M, Powell JA, Rieger F, Standish LJ (1986) The development of motoneurons in the embryonic spinal cord of the mouse mutant muscular dysgenesis $(m d g / m d g)$ : survival, morphology, and biochemical differentiation. Dev Biol 114:426436.

Oppenheim RW, Havenkamp LJ, Prevette D, McManaman JL, Appel SH (1988) Reduction of naturally occurring motoneuron death in vivo by a target-derived neurotrophic factor. Science 240:919-922.

Oppenheim RW, Bursztajn S, Prevette D (1989) Cell death of motoneurons in the chick embryo spinal cord: acetylcholine receptors and synaptogenesis in skeletal muscle following the reduction of motoneuron death by neuromuscular blockade. Development 107:331-341.

Oppenheim RW, Prevette D, Haverkamp LJ, Houenou L, Yin QW, McManaman J (1993) Biological studies of a putative avian muscle-derived neurotrophic factor that prevents naturally occurring motoneuron death in vivo. J Neurobiol 24:1065-1079.

Oppenheim RW, Prevette D, Wang SW (1996) The rescue of avian motoneurons by activity blockade at the neuromuscular junction. Soc Neurosci Abstr 22:44.

Oppenheim RW, Prevette D, Houenou LJ, Pincon-Raymond M, Dimitriadou V, Donevan A, O'Donovan M, Wenner P, McKemy DD, Allen PD (1997) Neuromuscular development in the avian paralytic mutant crooked neck dwarf $(\mathrm{cn} / \mathrm{cn})$ : further evidence for the role of neuromuscular activity in motoneuron survival. J Comp Neurol 381:353-372.

Orr-Urtreger A, Göldner FM, Saeki M, Lorenzo I, Goldberg L, DeBiasi M, Dani JA, Patrick JW, Beandet AL (1997) Mice deficient in the $\alpha 7$ neuronal nicotinic acetylcholine receptor lack $\alpha$-bungarotoxin binding sites and hippocampal fast nicotinic currents. J Neurosci 17:9165-9171.

Pittman RH, Oppenheim RW (1978) Neuromuscular blockade increases motoneuron survival during normal cell death in the chick embryo. Nature 271:364-366.

Pittman RH, Oppenheim RW (1979) Cell death of motoneurons in the chick embryo spinal cord: evidence that a functional neuromuscular interaction is involved in the regulation of naturally occurring cell death and the stabilization of synapses. J Comp Neurol 187:425-466.

Posada A, Clarke PGH (1999) Fast retrograde effects on neuronal death and dendritic organization in development: the role of calcium influx. Neuroscience 89:399-408.

Renshaw GMC (1994) [ [ $\left.{ }^{125} \mathrm{I}\right]-\alpha$-bungarotoxin binding co-varies with motoneuron density during apoptosis. NeuroReport 5:1949-1952.

Renshaw G, Rigby P, Self G, Lamb A, Goldie R (1993) Exogenously administered alpha-bungarotoxin binds to embryonic chick spinal cord: implications for the toxin-induced arrest of naturally occurring motoneuron death. Neuroscience 53:1163-1172.

Risau W, Wolburg H (1990) Development of the blood-brain barrier. Trends Neurosci 13:174-178.

Role LW, Berg DK (1996) Nicotinic receptors in the development and modulation of synapses. Neuron 16:1077-1085.

Sargent PB (1993) The diversity of neuronal nicotinic acetylcholine receptors. Annu Rev Neurosci 16:403-444.

Soler RM, Egea J, Mintenig GM, Sanz-Rodriquez C, Inglesias M, Comella JX (1998) Calmodulin is involved in membrane depolarizationmediated survival of motoneurons by phosphatidylinositol-3 kinase- and MAPK-independent pathways. J Neurosci 18:1230-1239.

Stewart PA, Wiley MJ (1981) Structural and histochemical features of the avian blood-brain barrier. Dev Biol 84:183-192.

Tanaka H (1987) Chronic application of curare does not increase the level of motoneuron survival promoting activity in limb muscle extracts during the naturally occurring motoneuron cell death period. Dev Biol 151:586-596.

Tang J, Landmesser L (1993) Reduction of intramuscular nerve branching and synaptogenesis is correlated with decreased motoneuron survival. J Neurosci 13:3095-3103.

Usiak MF, Landmesser LT (1999) Neuromuscular activity blockade induced by muscimol and D-tubocurarine differentially affects the survival of embryonic chick motoneurons. J Neurosci 19:7925-7939.

Xu W, Gelber S, Orr-Urtreger A, Armstrong D, Lewis RA, Ou NC, Patrick J, Role L, DeBiasi M, Beardet AL (1999) Megacystic, mydriasis, and ion channel defect in mice lacking the $\alpha 3$ neuronal nicotinic acetylcholine receptor. Proc Natl Acad Sci USA 96:5746-5751.

Zoli M, LeNovére N, Hill JA, Changeux J-P (1995) Developmental regulation of nicotinic ACh receptor subunit mRNAs in the rat central and peripheral nervous system. J Neurosci 15:1912-1930. 